\title{
Research Concerning Abutment Placement Training using a Navigation
} System

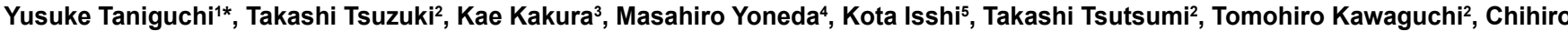 $\mathrm{Koga}^{6}$ and Hirofumi Kido ${ }^{3}$}

${ }^{1}$ Section of Crown and Bridge, Department of Oral Rehabilitation, Fukuoka Dental College, Japan

${ }^{2}$ Section of Removable Prosthodontics, Department of Oral Rehabilitation, Fukuoka Dental College, Japan

${ }^{3}$ Section of Oral Implantology, Department of Oral Rehabilitation, Fukuoka Dental College, Japan

${ }^{4}$ Section of General Dentistry, Department of General Dentistry, Fukuoka Dental College, Japan

${ }^{5}$ Central Dental Laboratory, Fukuoka Dental College Medical and Dental General Hospital, Japan

${ }^{6}$ Centre for Oral diseases, Fukuoka Dental College Medical and Dental General Hospital, Japan

\begin{abstract}
Purpose: In teaching practice, it is difficult to give adequate guidance to all students. The purpose of this research is to clarify whether teaching abutment placement using a support system (navigation system) that converts tooth axes to visual information provides guidance equivalent to an instructor.

Purpose and methods: Forty $5^{\text {th }}$-year undergraduate students underwent 2 training sessions total in 60 minutes concerning formation of the axial face of the $1^{\text {st }}$ maxillary molar. For the first training session, an instructor taught 20 students individually (guidance group); the remaining students used the navigation system (navigation group). The second session was without instruction, and students underwent evaluation of the abutment taper angle and buccolingual inclination based on 8 points. Furthermore, presence or absence of misalignment relative to adjacent teeth was assessed visually. Finally, we conducted a survey regarding use of the navigation system.

Results: Regarding the mean value of the taper angle, for all comparisons there was no significant difference between the guidance group and the navigation group. Regarding misalignment with adjacent teeth, erroneous formation was recognized in $100 \%$ of the guidance group for both mesial and distal and in $70 \%$ of the navigation group for both mesial and distal. In the survey, 18 students answered that the navigation system helped them recognize the taper angle.

Discussion and conclusion: Based on the results of this study, no significant difference was found in the taper angle between the guidance group and the navigation group. Furthermore, there was reduced misalignment with adjacent teeth in the navigation group. These results suggest that the navigation system could confer the same education effect as instructor guidance.
\end{abstract}

Keywords: Training for preparation of abutment teeth; Navigation system; Taper angle; Misalignment of adjacent teeth

\section{Introduction}

In the practice of teaching students, because methods for evaluation of the teaching of abutment tooth formation have been left up to the discretion of each instructor, objectivity has been poor, and there have been differences in training contents from student to student. In order to solve these problems, we have spent time establishing objective methods for evaluation through techniques such as instructor calibration and practical examination. Nevertheless, these problems have persisted, and there are still students who cannot successfully form an abutment surface. In the conventional style of practical instruction, the skill level of the instructor greatly influences teaching and evaluation $[1,2]$. Moreover, in order to allow students to correctly recognize tooth axes which are important for forming abutment teeth, it is necessary that there be separate instruction, which is a problem that increases the burden on the individual instructor. Additionally, when there are only a few instructors for students, it can be difficult for students to receive the appropriate instruction in the time allotted, which can make it a challenge even for students to recognize problems in abutment formation. It is expected that the application of digital technology to student education will improve these problems [3-6]. In recent years, a system for surgical support has been developed that converts the axes of the implant tooth into visual information [7]. Application of the system to abutment teeth implantation education is expected to be an effective method for improving the aforementioned problems.

Therefore, for the present study, we sought to clarify whether teaching abutment placement using a support system (navigation system) that converts tooth axes to visual information provides guidance equivalent to an instructor.

\section{Materials and Methods}

\section{Navigation system}

The navigation system (Inliant, Navigate Surgical Technologies; Navident, ClaroNav) is a support system that converts the tooth axes into visual information. For the present research, we applied the navigation system so that the axes of the abutment tooth were clearly visible during formation, making it possible to visually understand the tooth axes when the students were forming abutment teeth (Figure 1).

Scan templates were attached to the models used in our experiment (Invictus Dental Education Model, Nissin Dental Products Inc. Kyoto, Japan), CT images were obtained by scanning the model, data were combined by synchronizing the scan template attached to the turbine with an extraoral scanner, and the position of the turbine was displayed

*Corresponding author: $\mathrm{Dr}$ Yusuke Taniguchi, Departments of Ora Rehabilitation, Fukuoka Dental College, Fukuoka, Japan, Tel: 81928010411 E-mail: yuusuke@college.fdcnet.ac.jp

Received November 01, 2018; Accepted November 14, 2018; Published November 16, 2018

Citation: Taniguchi Y, Tsuzuki T, Kakura K, Yoneda M, Isshi K, et al. (2018) Research Concerning Abutment Placement Training using a Navigation System. Dentistry 8: 517. doi:10.4172/2161-1122.1000517

Copyright: @ 2018 Taniguchi $\mathrm{Y}$, et al. This is an open-access article distributed under the terms of the Creative Commons Attribution License, which permits unrestricted use, distribution, and reproduction in any medium, provided the original author and source are credited. 
Citation: Taniguchi Y, Tsuzuki T, Kakura K, Yoneda M, Isshi K, et al. (2018) Research Concerning Abutment Placement Training using a Navigation System. Dentistry 8: 517. doi:10.4172/2161-1122.1000517

on the CT image on a monitor. Therefore, when abutment teeth are formed, the tooth axes are visually represented by the dynamic tracking of the turbine and the monitoring of positional relationships.

\section{Practicum methods}

We targeted $40,5^{\text {th }}$-year students who had successfully passed their objective structured clinical examination (OSCE) and who were able to safely use the air turbine for the formation of the right 1st maxillary molar for 30-minute sessions total in 60 minutes. An instructor who is a Prosthodontics specialist taught 20 students individually (guidance group) for the first session, before these students were instructed to form abutment teeth in a practical exam; the remaining 20 students used the navigation system (navigation group) for the first session, then underwent a practical examination for the second session (Figure 2).

The abutment teeth formed in the practical examination were collected and evaluation of each abutment tooth was performed using the dental CAD/CAM system CEREC. The taper angle along with mesio-distal and buccal-lingual alignments was determined based on 4 corners using 8 points-clockwise from the lingual aspect $\mathrm{A}, \mathrm{B}, \mathrm{C}$,
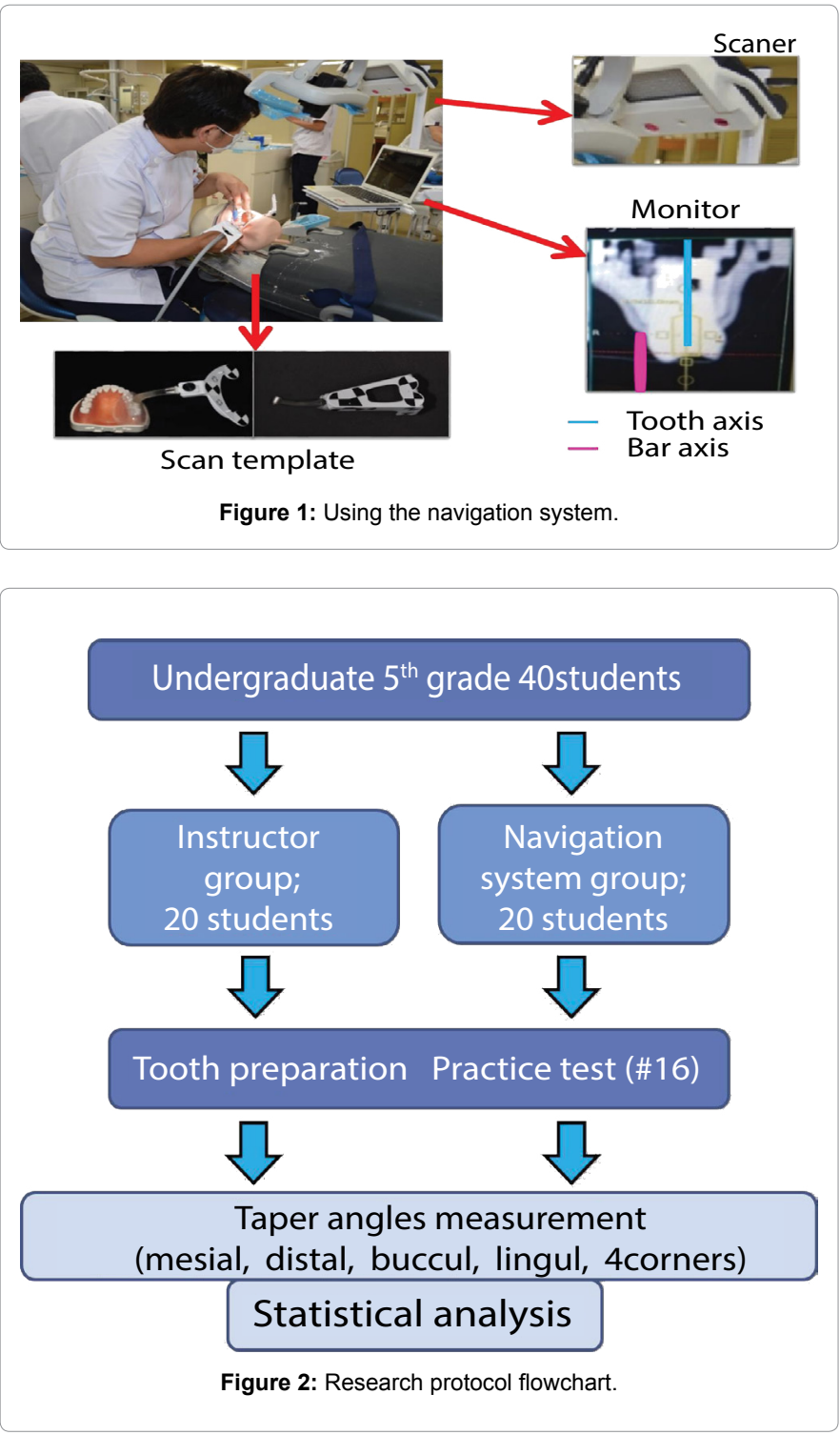

D, A', B', C', D' (Figure 3). Concerning our measurement methods, the collected abutment tooth was converted into data using a digital scanner. The taper angle is determined from the divided plane relative to the tooth axis. Measurement is performed from $0.5 \mathrm{~mm}$ above the finish line to the center of the crown. The taper angle was calculated as the average value (Figure 4). Furthermore, the presence or absence of misalignment relative to adjacent teeth was assessed visually.

After the practical examination, we conducted a survey regarding the use of the navigation system. Survey contents were as follows: "Was the navigation system easy to use?", "Did the navigation system help in forming the abutment?", and "Was the navigation system helpful for understanding the tooth axes for forming the abutment?

\section{Statistics}

All values are expressed as mean $+/$ - standard deviation ( $n$, number

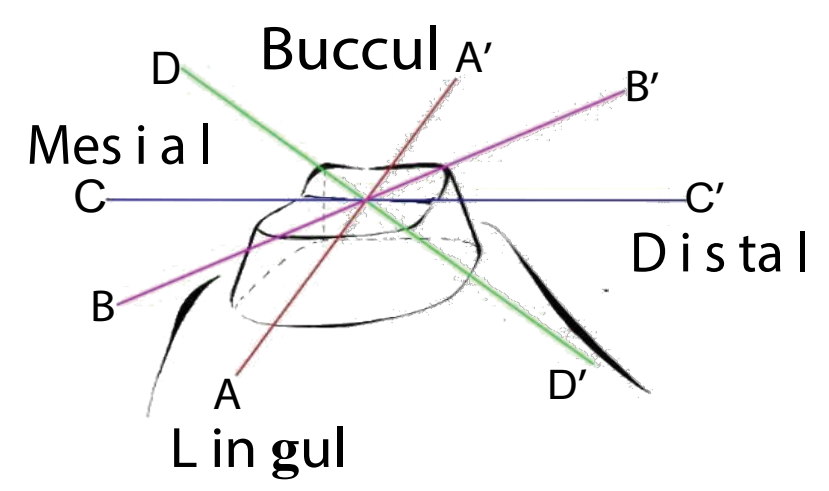

Figure 3: Measurement of the taper angle in an abutment tooth.

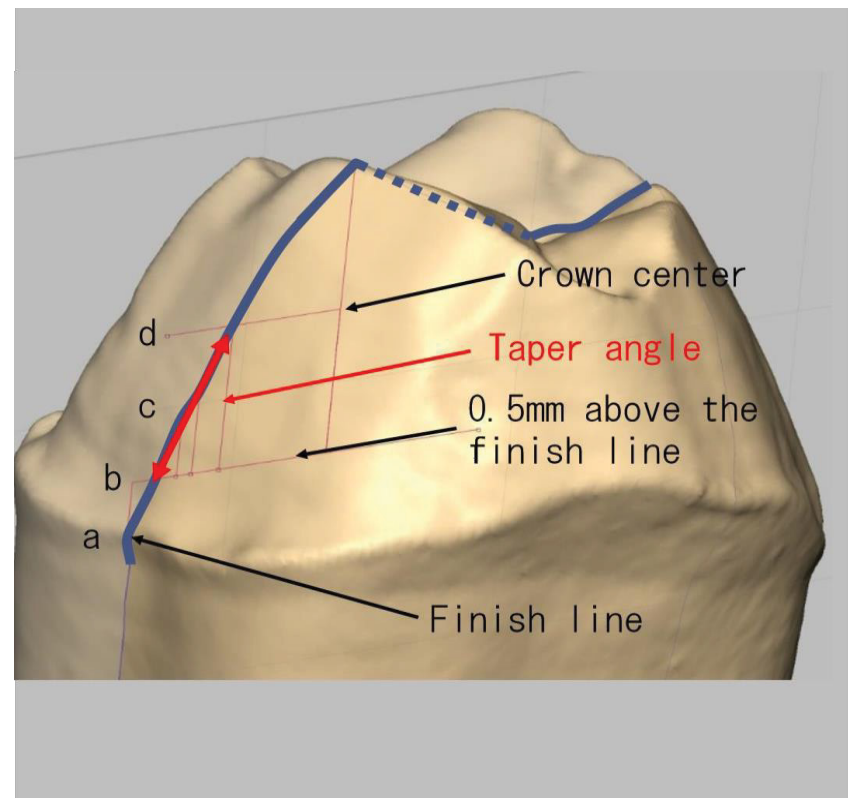

a. Finish line

b. $0.5 \mathrm{~mm}$ above the finish line

c. Taper angle

d. Crown center

Figure 4: Measurement of the taper angle in an abutment tooth. 

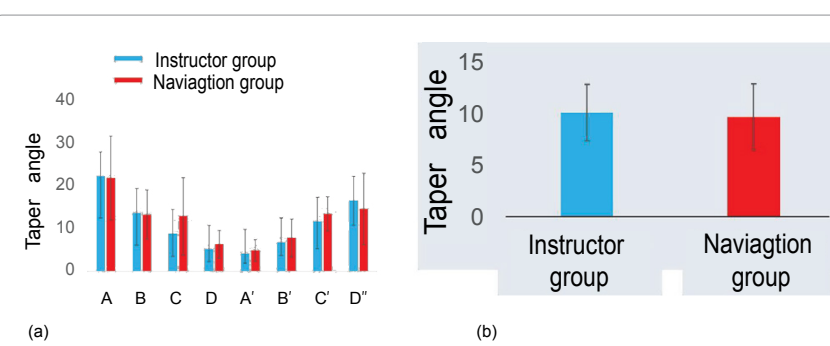

(a)

Figure 5: (a) Taper angle by site, (b) Taper angle by study arm.

\begin{tabular}{lcc}
\hline & $\begin{array}{c}\text { Instructor } \\
\text { group }\end{array}$ & $\begin{array}{c}\text { Navigation } \\
\text { group }\end{array}$ \\
\hline Mesial & $100 \%$ & $70 \%$ \\
Distal & $100 \%$ & $70 \%$ \\
\hline
\end{tabular}

Figure 6: Proportion of misalignment in each group.

of subjects). Statistical analyses were performed using SPSS version 19 (SPSS Inc., Chicago, Illinois) using Student's t-test or one-way analysis of variance (ANOVA) with repeated measures followed by Bonferroni's post hoc test. A significant difference was assumed when the p-value was less than 0.05 .

\section{Results}

Angles in the guidance group were as follows: $\mathrm{A}, 13.0^{\circ} ; \mathrm{B}, 8.5^{\circ} ; \mathrm{C}$, $7.5^{\circ} ; \mathrm{D}, 6.5^{\circ} ; \mathrm{A}^{\prime}, 4.9^{\circ} ; \mathrm{B}, 11.5^{\circ} ; \mathrm{C}^{\prime}, 12.8^{\circ} ; \mathrm{D}^{\prime}, 13.3^{\circ}$. Angles in the navigation group were: $\mathrm{A}, 13.2^{\circ}$; $\mathrm{B}, 7.0^{\circ}$; C, $8.2^{\circ}$; D, $5.9^{\circ}$; $\mathrm{A}^{\prime}, 6.1^{\circ}$; B', $10.6^{\circ}$; C', $14.1^{\circ}$; $\mathrm{D}, 12.7^{\circ}$. There was no difference between the guidance group and the navigation group at any measurement point. Furthermore, there was no significant difference between the taper angles of the guidance group and the navigation group at $10.0 \pm 2.7^{\circ}$ and $9.6 \pm 3.2^{\circ}$ respectively (Figure 5).

With respect to the presence or absence of misalignment of adjacent teeth, there was $100 \%$ mismatch observed for both mesial and distal aspects in the guidance group. In the navigation group, there was $70 \%$ misalignment observed in both mesial and distal aspects (Figure 6).

In the survey administered to the navigation group, six students answered that the navigation system was easy to use, whereas 10 students responded that it was cumbersome and difficult to use. There were 18 students who said that the navigation system helped them to recognize the taper angle of the abutment tooth; 16 students answered that the navigation system was effective at helping them gain a visual familiarity with the tooth axes.

\section{Discussion}

In education for abutment tooth formation, few instructors are often responsible for many students. They must teach students individually while also keeping track of progress for the whole group. In such an educational environment, instruction becomes focused on students who are slow in practical training and on students who ask questions. Questions have been raised that such an environment might not provide a stable teaching situation [8]. In particular, it is often difficult to instruct several students at the same time, as students benefit from individual guidance during the formation of abutment teeth. For this reason, it is common practice for students to engage in abutment tooth formation on their own and to ask the instructor to judge their performance after the fact. It has been reported that the taper angle of the abutment teeth formed by many students increased as the students have more freedom from individualized instruction in their design [9].

As a method for improving these problems, various systems of educational support for abutment tooth formation have been reported $[10,11]$. Nevertheless, these educational systems have not been applied to actual clinical practice. In the present study, a surgical support navigation system for converting tooth axes into visual information which has already been clinically applied to oral surgery was further applied to abutment tooth formation education. Since the tooth axes are displayed in real time, by using this system for the formation of abutment teeth, students can clearly recognize positions and angles at sites which are difficult to see, and it is possible to visually recognize the taper of the formed tooth angle. By using this navigation, students can self-learn abutment tooth formation without relying on instructors $[12,13]$.

In this study, there was no significant difference between the taper angle of abutment teeth of students instructed by an instructor and taper angle of abutment teeth self-learned by students using the navigation system. Based on this, it is suggested that the navigation system enables students to visually recognize the tooth axis of the abutment tooth without requiring individual attention from an instructor. Information of an abutment tooth, it is difficult to perceive the axial aspect of the bar at sites where visibility is difficult. Furthermore, if slicing is performed, there is the possibility of mistakenly drilling adjacent teeth unless the axial face is visualized [14].

In this study, the proportion of errors in alignment with adjacent teeth in the guidance group was $100 \%$ for both mesial and distal teeth. When students self-learned using the navigation system to form abutment teeth, the ratio of misalignment with adjacent teeth was $70 \%$ for both mesial and distal teeth. By applying the navigation system, students were able to visualize the tooth axes even at sites where visibility was challenging. This suggests the proportion of misaligned teeth is less with the use of navigation. There are many advantages to the navigation system, including that it does not need quite as large an opening compared to a guide stent, it is possible to drill the implant while grasping the bone surface, and easy injection of water, since the device used outside the mouth is large and the navigation system displays the implant axes in real time. If there is an error in the system, operations using the navigation system cannot be continued.

As part of this research, we interviewed students in the navigation group. There were many problems identified, such as the navigation system equipment being heavy and difficult to use, and the learning curve required to get used to the navigation system. Nevertheless, most students had a positive reaction and believed they were conscious of the taper angle when forming abutment teeth.

More than this, there are some problems when applying the navigation system to abutment tooth formation education, but it seems to be an effective educational adjunct for the future. Since it is necessary to clarify the problems of this system, we believe that further examination is required to determine the best ways to apply navigation to student education. 
Citation: Taniguchi Y, Tsuzuki T, Kakura K, Yoneda M, Isshi K, et al. (2018) Research Concerning Abutment Placement Training using a Navigation System. Dentistry 8: 517. doi:10.4172/2161-1122.1000517

\section{Conclusion}

In our model of training, it is suggested that the navigation system delivers the same educational effect as instructor-based guidance.

\section{References}

1. Iwanami K, Ogawa T, Shigeta $Y$, Ando E, Fukushima S (2006) A questionnaire investigation of criteria for evaluating abutment form preparation by instructor of dental students training. Journal of Japanese Association for Dental Education 22: $150-154$

2. Kasahara S, Okuyama Y, Kimura K (1997) Multivariate analysis of results of tooth preparation practice in manikin head with artificial gingiva: applying principal component analysis. The Journal of the Japan Prosthodontic Society 41: 835-842.

3. Ando S, Miyazaki M, Gionhaku N, Kuwta F, Ito K, et al. (2007) Educational effectiveness of virtual reality dental simulator on nihon university school of dentistry. Journal of Japanese Association for Dental Education 23: 121-127.

4. Abe T, Okuyama Y, Kasahara S, Kimura K (2009) Educational effect on tooth preparation of visual feedback using computer graphics. Annals of Japan Prosthodontic Society 1: 123-129.

5. Okuyama Y, Kasahara S, Kimura K (2005) Quantitative evaluation of axial wall taper in prepared artificial teeth. Journal of Oral Science 47: 129-133.

6. Tiu J, Cheng E, Hung TC, Yu CC, Lin T, et al. (2016) Effectiveness of crown preparation assessment software as an educational tool in simulation clinic: $A$ pilot study. J Dent Educ 80: 1004-1011.
7. Casap N, Wexler A, Persky N, Schneider A, Lustmann J (2004) Navigation surgery for dental implants: assessment of accuracy of the image guided implantology system. J Oral Maxillofac Surg 62: 116-119.

8. Shigeta Y, Ogawa T, Iwanami K, Matsuyama Y, Imai Y, et al. (2003) Application of problem-based learning method to a training curriculum for tooth preparation. Journal of Japanese Association for Dental Education 19: 67-73.

9. Nagy ZA, Simon B, Tóth Z, Vág J (2018) Evaluating the efficiency of the dental teacher system as a digital preclinical teaching tool. Eur J Dent Educ 22: e619-e623.

10. Furness AR, Callan RS, Mackert JR Jr, Mollica AG (2018) Limitations of surface mapping technology in accurately identifying critical errors in dental students crown preparations. J Dent Educ 82: 69-75.

11. Schweyen R, Beuer F, Bochskanl M, Hey J (2017) Implementing a new curriculum for computer-assisted restorations in prosthetic dentistry. Eur J Dent Educ. 22: e237-e247.

12. Block MS, Emery RW, Lank K, Ryan J (2017) Implant placement accuracy using dynamic navigation. Int J Oral Maxillofac Implants 32: 92-99.

13. Asbjorn J, Brenton W, Joseph F, David Powell, Eszter SG (2018) Investigational clinical trial of prototype optoelectronic computer-aided navigation device for dental implant surgery. Int J Oral Maxillofac Implants 33: 679-692.

14. Okuyama Y, Abe T, Kasahara S, Kimura K (2008) Objective assessment of damage to adjacent artificial teeth in tooth preparation education. Journal of Japanese Association for Dental Education 24: 170-174. 